\title{
Study on Red Yao Wedding Ceremony under the Perspective of Communication Ceremony
}

\author{
Daili Zheng \\ Guilin Tourism University, Guilin, Guangxi, 541006
}

Keywords: wedding ceremony; Red Yao; communication ceremony

\begin{abstract}
In the new phase of the development of modern material civilization and spiritual civilization, ethnic minorities have various degrees of development and reform on the basis of their own national traditions. Ceremonies differ in various ethnic traditional cultures. The inheritance of customs plays an important role in human life in the world.
\end{abstract}

\section{Introduction}

The Yao nationality is an ancient ethnic group and is mainly located in Hunan, Guizhou, Guangxi and Guangdong. The Yao people living in Libo County, Qiannan Buyi and Miao Autonomous Prefecture, Guizhou province have three major branches. They are used to being called Baikuyao, Qingwanyao and Changfeng Yao. Among them, the branch known as Qingwanyao mainly lives in Yao. Luyao Township. Yaoshao Yao Township is located in the eastern part of Libo County. There are 396 households and 1590 people in the township. All of them are Yao ethnic group. The main group is the Qingpu Yao branch. Yao is called "Suo Mao", and there are Yao, Wei, Lu, Ou, Liu and Mo. There are 11 surnames such as Yao and Yao, among which the Yaojiazhai and the up and down Weizhai are the largest Yao natural villages. The mountains are steep and steep, and the traffic is inconvenient. The traditional culture of the Yao people is well preserved. The marriage culture is ancient and unique. There are "marriage talks", mother-inflicted cattle, relatives, choice of days, go out, get a dowry, go through the door, make a new house, and return. Gates, thanks to marriage and other complex processes, has the significance of ethnological and anthropological research. However, under the influence of a growing mainstream culture, it is already in an endangered state.

\section{Ceremonial Communication Concept}

The ritual can be described as the oldest and most common social phenomenon in the long river of human culture and thus a new perspective in the field of news communication. It is well known that any culture must be disseminated before it can be passed on to the world. It is inherited by future generations. Here I will explain the concept of ceremonial communication from both narrow and broad perspectives. Narrowly speaking, the concept of "communication of ceremonies" ceremonializes the process of communication, that is, using ritual as a carrier of communication to directly transmit information; "broadcast concept of ritual" in a broad sense is mainly to create a belief that is universally recognized by the disseminating object. Connect them together so that the audience understands and accepts the information content in the process of subtle influence. James Kerry's "concept of ceremonial communication" achieves the maintenance of a community in terms of time through the sharing of information. It emphasizes not control and power, but sharing and communication. From a new perspective, he launched a study of the concept of communication rituals. In the article "As a Culture," he clearly pointed out that the concept of communicative communication emphasizes the study of human behavior itself, attaches importance to the transmission and acquisition of information, and focuses on a certain ritual. Dramatic behavior. James Kerry's study of the communicative concept of propaganda launched from a new perspective of salary does not simply treat the process of communication as the transmission or acquisition of information between individuals. Instead, it considers people as participating in a sacred mass. 
ceremony". In fact, James Kerry inspected communication from the perspective of culture and redefined the communication under the ritual view. "Propagation is a symbolic process in which reality can be produced, maintained, corrected, and transformed.”

Through ceremonies you can inherit tradition and impart knowledge. The historical tradition of a nation is irreplaceable. The ritual is created by the nation in its formation and development. It is the crystallization of the collective wisdom formed by the nation in its interaction with nature and society. Therefore, it gradually accumulates. Once it is formed, it has a very strong vitality. As long as this nation still exists, then the ritual will be inherited from generation to generation in the traditional form, and it is difficult to interrupt.

The ritual is the result of the selection of human beings in the specific historical period of time and has a certain historical mark. Therefore, rituals are not solidified, and ancestral inheritance is by no means a simple follow-up. Traditional ritual propagation will inevitably continue to mutate and create in the process of inheritance. The Uyghur wedding ceremony has become a "classroom" that has been inherited and followed traditional culture. Through repeated performances, it conveys the Uyghur society's spiritual concepts, moral standards, and emotional trends to everyone attending the wedding through its repeated and intuitive performances., And subtly affect the behavior of the villagers. In reality, the same type of ceremonies exhibit functional changes in different historical periods, such as gradual shrinkage, weakening, loss, extension, and innovation, etc., and they are constantly increasing or decreasing in order to adapt to changes in environmental conditions. .

Like culture, culture is the crystallization of national wisdom in a certain area. It is the basic basis and business card that exists in the human world and has the most solemn symbolism. It goes deep into the deep and even unconscious consciousness of each member as a nation's internal rules. Ethnic members consciously or unconsciously accept and inherit all of this, and spread it through symbolic rituals.

\section{Marriage Types of Red Yao Society and Wedding Ceremony as Transition Etiquette}

The marriage of uxorilocal marriage is the main type of marriage in Lingzhai, but it is also very common to recruit marriage and "two-headed" marriage. Since the Yao ethnic group is a migrating mountain ethnic group, it has always been good at swimming. Although Hongyao built an early settlement, it still has difficulties in producing a wide variety of crops. This type of farming requires more labor. Recruiting marriages and top-of-the-range marriages have largely eased the problem of labor stress. According to the author's statistics, out of the 144 couples in Lingzhai, 93 were married to male prostitutes, accounting for $65 \%$ of the majority; 29 pairs were recruiting marriages, accounting for 20\%; 22 pairs were top marriages, accounting for $15 \%$. Marriage refers to the fact that women do not marry, and they recruit men to marry at home, also known as "Lang Lang." The conclusion of the procedure is simpler than that of male prostitutes who do not remarry and dowry. After the parties have agreed on the marriage, they choose to welcome the "Lang Tsai" to enter the door. The woman feasts with her uncle and uncle and brings her to identify with her. After entering a woman's family, a female daughter-in-law does not change her surname and is not subject to discrimination and has the right to inherit property. However, childbearing children are all accompanied by the woman's surname, Chengding female Fang Zongxi.

"Two heads" marriage is also called "two sides go" and "two heads live". It means that both men and women have no fixed residence after marriage, but instead live in the same labor for both parents for a period of time. Husband and wife enjoy the property of their parents' land and labor tools, and share the responsibility of taking care of the young and old of both families. They have the task of extending the confinement of both families at the same time, so they must have at least two children. If there are more than three children, the two parties agree that the ancestral hall of either of the heads should be evenly distributed. The two parties who concluded the two top marriages must not be too far away from each other. The number of villages in Zhaishui, which are within the Zhai Nei and the neighboring areas, are more. Two heads of marriage are mainly produced under the following three conditions: First, both men and women are either the boss or the main labor force in the family. Whether it is a married woman or a lone family will affect the 
production and living of one of the families. Therefore, both parties will implement dual-headed residence. Second, both parties are the only child in the family and have the responsibility of succession; or if one of them is the only child and does not want to marry or come to the door, it can only be married. Third, the elderly and middle-aged and elderly widows remarried to organize families. Both sides have children. Remarried couples raise their own children and live in two places. In the history of Hongyao, prevalence of early marriage is generally prevalent. The age of marriage is not good for every single person. The ages of 15, 17, and 19 are appropriate. Men over the age of 17 and women over 15 can be married. Before the 1950s, Yao marriages were mostly arranged by parents. After the founding of New China, they gradually transformed into free love. Whether it is through free love or contracted marriages, they must go through the process of "promoting big kisses" that include media, quasi-intelligence, combination of characters, marriage, media, marriage, weddings, and marriage. "Two-headed" marriage and recruiting marriage is relatively simple, especially the lack of a grand process of sending relatives, welcoming parents. Since the 1980s, the traditional wedding ceremony of "promoting big relatives" has been gradually simplified. Nowadays, it is common for husbands and wives to jointly produce "double happiness" with children of three dynasties, and more and more people have concluded "two heads" marriages. After the implementation of family planning, the Hongyao family generally has only one or two children. As one of the aspects of life etiquette, weddings are a typical transitional etiquette (or ceremonies) that have become the consensus of the academic community. In "Transitional Etiquette", Fangenep described the unified theoretical model that he summed up from various rituals, whether in the life or development of individuals, in space, time, or social status. "It is all along with the process of transitional ceremonies from one position to another and from one to another (universal or social)." Most of this transition is related to the division between the sacred world and the secular world. Such ceremonies have a common ritual process and a three-phase model, namely, separation etiquette (separation ceremony), marginal (transitional) etiquette, and aggregation (combination) etiquette, also known as pre-threshold, threshold, and post-threshold etiquette. Pre-threshold refers to the separation of ritual subjects (individuals or groups) from previous social structures or cultural scenes, entering the threshold period of the transitional state, ambiguity in status, identity, and role, and re-emphasizing the ritual stage. Return to the clearly defined social structure and life. The "transition etiquette" and "threshold" theories have taken note of the dynamism of the ritual. "There is a mode of significance for the analysis of people's stages in society. It socializes the physiology of human life and the physical nature of life stages. Process and socialization were integrated together in ritual theory. The significance of transitional etiquette for individuals from natural persons to social individuals is based on the recognition of human physical attributes. In recent years, physical research has enriched the understanding of this issue. Body sociologist Chris Schilling pointed out: "The most beneficial way to sort out the concept of the body is to sum up the body as a biological and social phenomenon, because it enters and participates in It is this biological and social characteristic that makes this phenomenon of the body both unobtrusive and elusive.” 12 The introduction of physical research perspectives helps expand the transition to tradition. Etiquette research, and deepen the discussion of people's ideas and socialization.

In Hong Yao society, the separation of infants and mothers does not represent the birth of a person with a gender and social role. "People" is a concept of culture, and it is also an entity that continuously develops and changes during socialization and through rituals. Marriage and childbearing is an important turning point for "adults," because people in Hongyao believe that only those who continue their children's lives will be able to live their lives. Marriage marriage takes the bride as the main threshold person. The separation ceremony takes place in the space scene of the foreign family, including eating and cooking rice, purifying the body, and mounting the body, and the brothers go out to the door. Through these symbolic actions of the body, the bride walks out of the previous social structure, Outside the home, and do not take away their blessings and financial principles. The scenes of the transitional ceremony were transferred to the sending of pro-marriage and singing ancestry, and the witchcraft that was sent to the progeny could eliminate the dangers of 
the newly-married and marginalised brides at the moment of the birth of the new me and the old ones, as well as the evil spirits that were emitted from them to others. The "Bridal Room" set on the night of wedding wine prolongs the bride's transition time. On the one hand, it is conducive to the physical and psychological adaptation of the bride; on the other hand, it provides space and social support for the transformation of her identity from daughter to daughter-in-law; The act of reciprocal and affiliation in the song hall reinforces the significance of this status change for the in-laws. Combining the ritual with the symbolic body of witchcraft combined with the combination of petitions or divination couples is influenced by the positive factors of sexual witchcraft and the negative factors of divination. The ceremonial ritual ritual emphasizes the combination of the bride's and her family's kinship. The identities of the wife and the newly-married facts are also open to the public witness.

\section{Conclusion}

From the "natural" body's cultural (social) transformation perspective, revealing the transitional ceremonies of weddings and other transitional rituals is not only a continuation of the anthropological thinking of man's dual nature, but also a "natural-cultural" dualism that has always existed in the social science community. The attempt, as Schilling put it, said: "The division of the natural-cultural dualism is neither necessary nor useful. The body is not merely constrained by social relations or injected into social relations, but is actually constructed. These relationships.

\section{References}

[1] Wang Xiao. Research on the Protection and Utilization of Weifang Intangible Cultural Heritage during the Period of "After Shen Shi Yi"[D]. Jinan: Shandong University, 2014.

[2] Gao Xiaokang. Towards the Protection of Traditional Culture in the Period of "After Shen Shiying"[J]. Journal of Jiangsu Administration Institute, 2012(2):39-46.

[3] Ma Ni. Contemporary China's Cultural Consciousness and Cultural Innovation: From Fei Xiaotong's View of Cultural Consciousness[J]. Social Sciences Journal, 2013 (3): 42-45.

[4] Xiang Yunqi. On "Cultural Space" [J]. Journal of the Central University for Nationalities (Philosophy and Social Sciences), 2008(3):81-88.

[5] Kong Lingping. Inheritance and Protection of Folk Dance under the View of Festival Cultural Space [J]. Festive Study, 2015(2):55-63. 